\title{
Understanding the variability in sheep and beef farm profitability
}

\author{
B. W. HAWKINS, S. WU \\ Harmonic, Wellington \\ Bridgit@harmonic.co.nz
}

\begin{abstract}
A wide variation in profitability exists between farmers across New Zealand. Not all of this variation can be simply attributed to land class, absolute production levels or debt levels. Understanding what makes one farmer profitable when another struggles to break even is necessary to enable the development of programmes and support to improve the overall sector's profitability. This paper reports on the results of exploratory analysis on North Island hard hill country to identify what factors are linked to the large variation in profitability observed between farms. The exploratory analysis used simple correlation analysis to study the relationship between selected farm attributes to identify those that appear most important to determining overall farm profitability. The initial results indicated that on Class 3 farms stocking rate, sheep to cattle ratio and lambing percentage are important variables related to profit. As with any business, realising the profit potential of a farm is the combination of a well thought through strategy and sound execution. The variables identified in this exploratory analysis are core parts of the strategy, but to realise the profit potential, implementing these has to be tailored to the farm.
\end{abstract}

Keywords: profit, hill country, stocking rate, sheep to cattle ratio, lambing percentage, EBITR (Earnings before Interest, Tax and Rent)

\section{Introduction}

The New Zealand sheep and beef sector is under pressure to maintain its place as a significant contributor to New Zealand's GDP. Financial viability is challenging as product prices have fallen, input prices have risen and a series of adverse climatic events has occurred over the past decade. Coupled with the pressure of changing land use (dairy and dairy support on better country and forestry on poorer country) the sector is struggling to remain stable. But in this environment some farmers have managed to prosper and others have incurred large losses, year on year, surviving on equity. This paper addresses the factors that might contribute to the observed variation in profitability on North Island Hard Hill Country.

The annual farm survey data from the Economic Service Database maintained by Beef + Lamb New Zealand is used as the basis for all the analysis reported in this paper. This database has been used to map trends in productivity and profitability across each of the eight defined farm classes. Beef + Lamb New Zealand commissioned Harmonic to undertake additional analysis on this database to endeavour to identify the key features of profitable sheep and beef farms. The project is ongoing and this paper reports on the results of the initial exploratory stage. The goal of the work was to identify the key factors involved in profitability, but not at this stage their ranking or contribution to variation or the statistical significance of any observed effects. The results presented are a starting point to consider what underlies the increasing variation in profitability between farms, to indicate the major factors involved. For a farmer wanting to improve profitability it provides a place to start.

The survey results are classified into eight farming sub-groups based on topography, location and farm system. This paper reports only on results from analysis of farm survey data from Class 3: North Island Hard Hill Country. This class is characterised by steep hill country and low fertility soils.

\section{Method}

In the initial exploratory phase of the study simple correlation analysis was used to study the relationship between selected farm attributes related to profitability that are reported in this paper. A number of other statistical techniques such as cluster analysis were also used to further explore the data when appropriate. The initial analysis was focused on identifying potentially important relationships and did not attempt to measure statistical significance at this stage.

The factors that affect profitability are many and span the physical resources and constraints of the farm, the levels of production and price achieved, and the farmers themselves. By focusing the analysis on one farm class, Class 3, this takes out some of the variation due to the physical resource of the farm. The Economic Service data contains very detailed information on production and prices for the farms in the sample, but there is no data available on the farmer. This limitation means that the analysis can only address the underlying reasons for some of the observed variation in farm profitability and does not endeavour to explain the variability due to the important "people" factor. 
For the purposes of this stage of analysis the measure of profitability chosen was Earnings before Interest, Tax and Rent (EBITR). It has been normalised to EBITR per hectare in most cases to make profit more comparable at an individual farm level. This is a straightforward measure that is calculated using only actual income and expenses. The limitation of EBITR is that it does not account for the equivalent of a manager's salary if the farm is owner operated. However in Class 3 the majority of farms in the survey are owner operated and so there is little impact of this variation.

The majority of the analysis was undertaken with data from the 2008/09 financial year, the latest year data was available. To confirm trends and patterns observed from the initial analysis, time series analysis of the previous 5 years to $2008 / 09$ was also undertaken.

There were a total of 1258 farms categorised as Class 3 in 2008/09, and the survey sampled 69 farms of these. The farms in the survey are selected by a stratified sampling process, and across all farms the survey aims to replace $10-15 \%$ each year.

\section{Results}

The initial stage of the investigation confirmed that not only is there a wide variation in profitability between farms within each class in the Economic Service survey, but also the extent of the variation has increased over time. Figure 1 illustrates the way the distribution and variability of profitability have changed between 1994/95 and 2008/09. The distribution for 2008/09 shows much longer "tails" in the curve at both ends but has a greater median EBITR per hectare compared to the 1994/95 financial year. The plot shows that despite having more farms with relatively higher profit in 2008/09, there were also more with greater losses compared to fifteen years previously. The data has been standardised to 2009 dollars using the CPI index.

The increased spread in profitability has exacerbated the difference between the profit of a top performing farm and one close to the median. In 2008/09 a farm in the 80th percentile achieved an EBITR of $\$ 268.10$ per hectare compared to the median of $\$ 170.70$ per hectare. The average size of Class 3 farms is 779 hectares, meaning a farm in the 80 th percentile made on average an additional $\$ 75874.60$ in $2008 / 09$ compared to the median.

To uncover the key variables that underlie this significant difference in profitability, the first stage of the exploratory analysis investigated difference in the building blocks of a farm system, namely, stocking rate, and sheep to cattle ratio.

\section{Stocking Rate}

Figure 2 appears to show that on average the most profitable farms within Class 3 have a higher stocking rate compared to those farms ranking in the middle and bottom $20 \%$ brackets. This effect was observed in all but one of the previous 6 years. In 2007/08 farms with a stocking rate greater than $10 \mathrm{SU} /$ ha had the lowest median EBITR/ha. There were large areas of the country affected by drought in this year.

Stocking rate alone did not determine profitability and needs to be reviewed in conjunction with other variables to fully understand its effect on profit.

\section{Sheep to cattle ratio}

Another key farm system feature in Class 3 is the sheep to cattle ratio. Figure 3 compares the distribution of sheep to cattle ratio for the top, middle and bottom $20 \%$ of farms. There is a non-linear relationship between sheep to cattle ratio and EBITR, and the plot appears to show that there is threshold ratio to realise the benefit of cattle in a system, but if this is moved too far the benefits reverse. Reviewing the previous 6 years showed a clear pattern that the consistently top performing farms had a sheep to cattle ratio between 60-65\% sheep compared to the poorest performing farms which had ratios in each year spanning $50-75 \%$.

\section{Stocking rate and sheep to cattle ratio relationship}

Further analysis was undertaken to investigate the relationship between sheep to cattle ratio in combination with stocking rate and EBITR. The results were not conclusive and due to the relatively small sample size care must be taken in drawing conclusions, but it appears that in Class 3 farms stocking rate has a key role in overall profitability. The most profitable farms generally had higher stocking rates and median (64:36) sheep to cattle ratios. The worst performing farms generally had stocking rates at or below the median of $8.3 \mathrm{SU} / \mathrm{ha}$ and a wide variation in sheep to cattle ratio. The middle performing farms clustered around the median stocking rate of $8.3 \mathrm{SU} /$ ha and had sheep to cattle ratios above the median of $64: 36$.

\section{Lambing percentage}

Not surprisingly there is a strong relationship between lambing percentage and EBITR/ha. Figure 4 shows this relationship and identifies that the top $20 \%$ of farms almost all have a lambing percentage above the median in $2008 / 09$ of $104.7 \%$ and some achieving significantly higher percentages than this.

Some of the factors that contribute to lambing percentage were also investigated and shown to have a positive relationship to overall profitability. Farms that undertook scanning achieved a 5\% median lambing percentage higher than farms that undertook no scanning. The act of scanning itself clearly does 


\section{Figure 1}

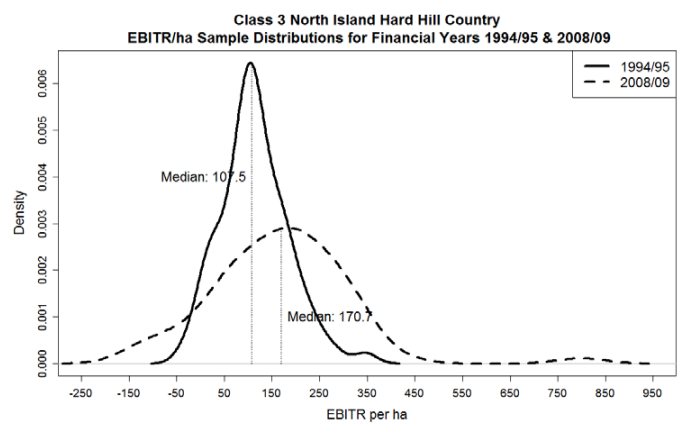

Figure 3

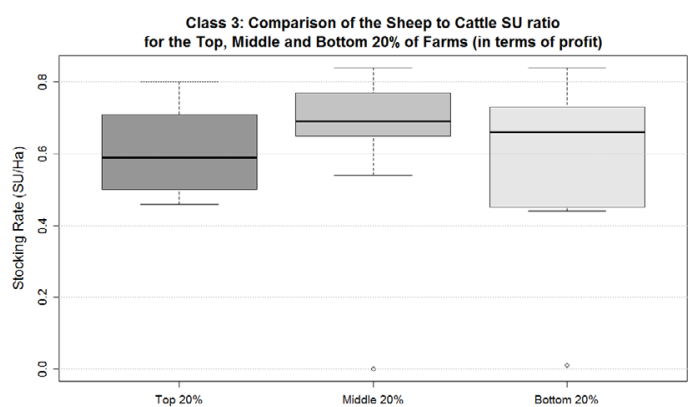

not increase lambing percentage, but the information gathered from scanning can be used to manage differently to achieve a higher lambing percentage. The top $20 \%$ of farms scanned between $90-100 \%$ of ewes compared to the bottom $20 \%$ of farms where only $25 \%$ of farms scanned $100 \%$ of ewes and nearly $40 \%$ of farms undertook no scanning at all.Top performing farms all mated later than 1 April compared to the bottom performing farms all mating prior to 1 April.

A higher lambing percentage appears associated with a greater proportion of store sales and decreased average lamb sale weight but, as Figure 5 shows, the positive effect of a higher lambing percentage was more important to overall profitability.

\section{Stability of farm system}

A drawback of analysing data from one year only is that as the farming enterprise is a biological system the effects of an action can sometimes take more than one year to be observed. A criticism made of annual survey data is that a farm may appear profitable in a year due to an unsustainable practice, such as deferring capital fertiliser, or an adverse climatic event. To test the conclusions drawn in this analysis, many of the initial results were then tested over a six-year period. On some occasions the result appeared to be observed only in the 2008/09 year, but generally the results were consistent. Another observation from the time series analysis is that the most profitable farms tended to have consistent
Figure 2 The boxplot is a way of viewing distribution. The area within the box represents $50 \%$ of all the measurements and the thick black line is the median. The area between the dotted lines represents $95 \%$ of all the measurements.

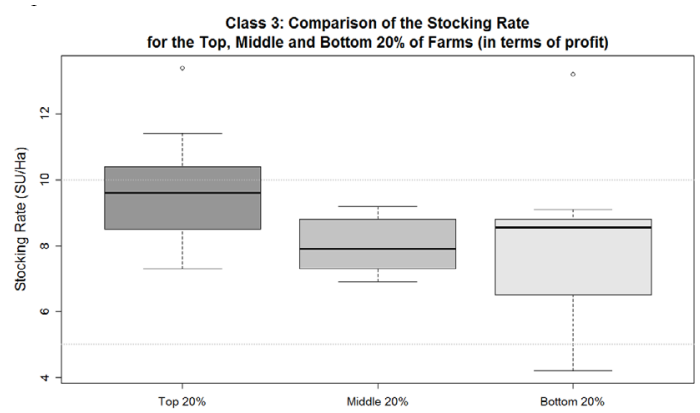

Figure 4

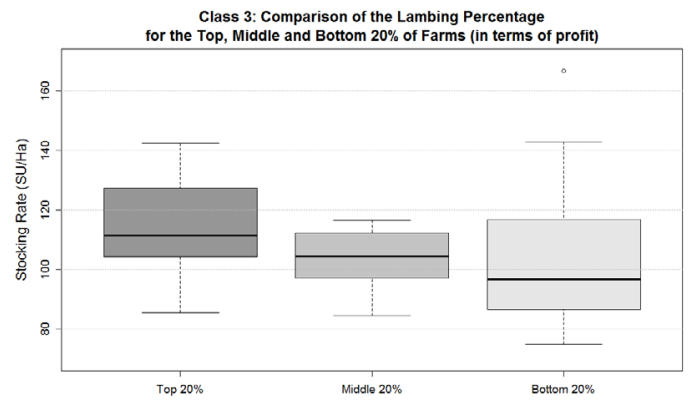

policies, such as fertiliser spending and stocking rate, compared to lower performing farms. Figure 6 gives an example of this observation. The time series plots show the mating date of top performing farms that were consistently in the survey over the 6-year period and the lower performing farms. The former show almost no variation between years and the latter show much more change, with most farms changing their mating date in each of the six years.

\section{Discussion}

The analysis confirms that there is a growing segment of North Island Hill Country farms that are making a loss from the farming enterprise. However there is also a growing segment of farms on the same land class that are achieving annual profits. Understanding what is done differently on profitable farms may lead to the development of targeted resources for farms that are struggling to be viable and want to improve overall profitability.

What makes a farm profitable and how this is achieved is complex; however the analysis shows that on Class 3 farms the very basic farm system decisions of stocking rate and sheep to cattle ratio must be set correctly for the farm to achieve the highest levels of overall profitability. Stocking rate is the most important variable to optimise in the farm system, and there is a non-linear relationship with sheep to cattle ratio. 
Figure 5 Pair-wise scatter plots for the sheep account/ha, prime to store sales ratio, stocking rate, lambing percentage and average lamb sale weight

The scatter plot shows the relationship between different variables. The steeper the line and more concentrated the data points, the stronger the relationship. This does not indicate if the relationship is statistically significant, but does highlight relationships that are of interest to investigate further. The distribution curve on the diagonal line is the distribution for that variable. These plots show that there is a positive relationship between sheep account (\$/ha) and lambing percentage, but no clear relationship between sheep account and average lamb sale weight.

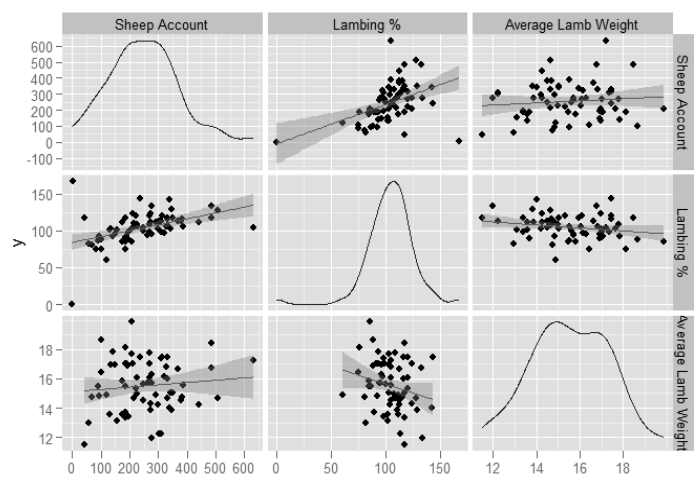

Once the stocking rate and sheep to cattle ratio are set at the optimum level, the analysis shows that the most profitable farms over time do not make erratic changes to these variables, or to other important farm system attributes.

Lambing percentage is positively related to profitability. Even though the analysis showed that increased lambing percentage was linked to lower lamb sale weights, this was out-weighed by the larger number of lambs for sale.

The Economic Service Database resource provides a unique opportunity to investigate the attributes of profitable farms. The analysis discussed in this paper is a segment of the initial exploratory analysis undertaken and focuses on the attributes that appear most important for determining overall profitability.

The next stage of this project involves further analysis to identify the statistical significance of the findings and the interdependencies between variables. The results presented in this paper give an indication, for Class 3 farms, of variables that are involved in profitability.

\section{Figure 6}
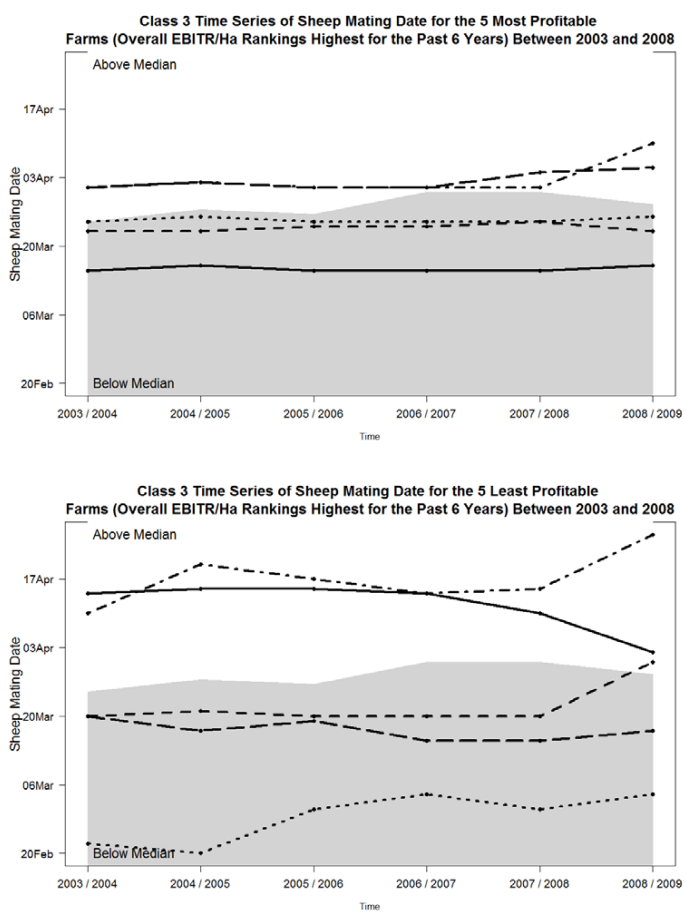

Before making a change to the overall farm system, it is important that the flow-on effects of that change are thought through taking into account the specific attributes of the farm. This is making sure that both strategy and execution are done well. A business can have a great strategy but be let down by poor execution. Likewise, without a sound strategy even the best execution will not deliver top results. Getting the strategy right to deliver a better than average profit for a Class 3 farm will involve setting the stocking rate and the sheep to cattle ratio at an optimal level for the farm, and aiming for a top lambing percentage. But to achieve the profit, the execution has to be right. This will involve ensuring that feed requirements are met, and good decision-making, and it will take time.

\section{ACKNOWLEDGEMENTS}

The authors gratefully acknowledge the support of Beef + Lamb New Zealand to present this paper based on some of the project undertaken by Harmonic investigating the profitability of sheep and beef farms. 